\title{
Contrast agent and radiation dose reduction in abdominal CT by a combination of low tube voltage and advanced image reconstruction algorithms
}

\author{
Nico Buls • Gert Van Gompel • Toon Van Cauteren • \\ Koenraad Nieboer • Inneke Willekens • Guy Verfaillie • \\ Paul Evans • Sven Macholl • Ben Newton • Johan de Mey
}

Received: 24 June 2014 / Revised: 15 September 2014 / Accepted: 14 November 2014 /Published online: 29 November 2014

(C) The Author(s) 2014. This article is published with open access at Springerlink.com

\begin{abstract}
Objectives To assess image quality in abdominal $\mathrm{CT}$ at low tube voltage combined with two types of iterative reconstruction (IR) at four reduced contrast agent dose levels.

Methods Minipigs were scanned with standard $320 \mathrm{mg} \mathrm{I} / \mathrm{mL}$ contrast concentration at $120 \mathrm{kVp}$, and with reduced formulations of $120,170,220$ and $270 \mathrm{mg} \mathrm{I} / \mathrm{mL}$ at $80 \mathrm{kVp}$ with IR. Image quality was assessed by CT value, dose normalized contrast and signal to noise ratio (CNRD and SNRD) in the arterial and venous phases. Qualitative analysis was included by expert reading.

Results Protocols with $170 \mathrm{mg} \mathrm{I} / \mathrm{mL}$ or higher showed equal or superior CT values: aorta (278-468 HU versus $314 \mathrm{HU})$; portal vein (205-273 HU versus $208 \mathrm{HU}$ ); liver parenchyma (122-146 HU versus $115 \mathrm{HU})$. In the aorta, all $170 \mathrm{mg} \mathrm{I} / \mathrm{mL}$ protocols or higher yielded equal or superior CNRD (15.0 28.0 versus 13.7$)$. In liver parenchyma, all study protocols resulted in higher SNRDs. Radiation dose could be reduced from standard $\mathrm{CTDI}_{\mathrm{vol}}=7.8 \mathrm{mGy}(6.2 \mathrm{mSv})$ to $7.6 \mathrm{mGy}$ (5.2 mSv) with $170 \mathrm{mg} \mathrm{I} / \mathrm{mL}$.

Conclusion Combining $80 \mathrm{kVp}$ with IR allows at least a $47 \%$ contrast agent dose reduction and $16 \%$ radiation dose reduction for images of comparable quality.
\end{abstract}

N. Buls $(\bowtie) \cdot$ G. Van Gompel · K. Nieboer · I. Willekens •

G. Verfaillie $\cdot$ J. de Mey

Department of Radiology, Universitair Ziekenhuis Brussel

(UZ Brussel), Laarbeeklaan 101, 1090 Brussels, Belgium

e-mail: Nico.Buls@uzbrussel.be

N. Buls · G. Van Gompel • T. Van Cauteren · K. Nieboer •

I. Willekens $\cdot$ J. de Mey

Research group LABO, Vrije Universiteit Brussel (VUB),

Brussel, Belgium

P. Evans $\cdot$ S. Macholl $\cdot$ B. Newton

Department of Medical Diagnostics, GE Healthcare,

Amersham, Buckinghamshire, England
Key Points

- There is a balance between image quality, contrast dose and radiation dose.

- Iterative reconstruction has a major, positive impact on this balance.

- Both contrast dose and radiation dose can be reduced in abdominal CT.

- The trade-off can be quantitatively described by a 3D model.

- Contrast and radiation dose can be tailored according to specific safety concerns.

Keywords Contrast media $\cdot$ Safety $\cdot$ Abdomen .

Multidetector computed tomography $\cdot$ Radiation protection

$\begin{array}{ll}\text { Abbreviations } \\ \text { CNR } & \text { Contrast to noise ratio } \\ \text { CNRD } & \text { Dose normalized contrast to noise ratio } \\ \text { CT } & \text { Computed tomography } \\ \text { CTDI } & \text { Volume computed tomography dose index } \\ \text { DLP } & \text { Dose length product } \\ \text { E } & \text { Effective dose } \\ \text { FBP } & \text { Filtered back projection } \\ \text { IR } & \text { Iterative reconstruction } \\ \text { ROI } & \text { Region of interest } \\ \text { SD } & \text { Standard deviation } \\ \text { SNR } & \text { Signal to noise ratio } \\ \text { SNRD } & \text { Dose normalized signal to noise ratio }\end{array}$

Introduction

In contrast-enhanced computed tomography $(\mathrm{CT})$ there is a balance between image quality, the amount of iodine injected and radiation dose. During the past decade, advances in CT technology provided us with ongoing opportunities to 
improve image quality. Because of this evolving technology, contrast media dosage should be continually revisited [1]. Two recent approaches that have a major effect on image quality are low-tube-voltage imaging and iterative reconstruction. Use of a low tube voltage, such as 100 or $80 \mathrm{kVp}$, results in higher iodine contrast enhancement because the mean photon energy approaches the iodine k-edge of $33 \mathrm{keV}$ [1, 2]. This approach has been widely reported in CT angiography with respect to radiation dose optimization [3-6], contrast agent dose reduction $[2,7,8]$ or both [9-13]. Contrast dose reduction is of particular interest for patients with renal dysfunction since contrast-induced nephropathy is closely related to pre-existing renal insufficiency and the amount of contrast injected. However, at the same time, image noise and susceptibility to beam hardening artefacts increase at lower tube voltage. This has prevented its clinical implementation, particularly for abdominal CT. One solution to increase image quality is an increased tube current to counterbalance noise levels at low tube voltages $[2,5,6]$; however, this requires high-power generators and may come at the cost of increased radiation dose, especially with larger patient sizes. Another solution is found in recent raw data-based iterative reconstruction (IR). IR techniques can be based on hybrid (which combines statistical IR approaches with standard filtered back projection, FBP) or pure IR methodology [14]. Significant noise reductions and improved diagnostic confidence are reported with both types [15-21]. While studies reported the possibility of contrast agent dose reduction with low tube voltage imaging, to our knowledge, the impact of combining this with advanced types of iterative reconstruction has not been investigated for a wide range of contrast agent doses. The purpose of our study was, therefore, to prospectively compare image quality in abdominal $\mathrm{CT}$ at a low tube voltage $(80 \mathrm{kVp})$ combined with full and hybrid iterative reconstruction at four reduced contrast agent dose levels with a standard tube voltage $(120 \mathrm{kVp})$ using FBP reconstruction and standard amount of contrast agent dose.

\section{Materials and methods}

Authors with no ties to GE Healthcare (Amersham, UK) (N.B., G.V.G, T.V.C., K.N., I.W., G.F. and J.D.M.) had complete unrestricted access to study data and unrestricted control over the data during the study. We used a porcine model to evaluate the image quality and radiation dose during the arterial (abdominal aorta) and venous (liver parenchyma and portal vein) phase. All CT examinations were performed on a 64-slice CT system (HD750, GE Healthcare, Waukesha, Wis). Prior to the porcine study, a phantom study was performed to select key iodine concentrations for the animal experiments.
Phantom study

Nine plastic test tubes with varying concentrations of iodinated solutions ranging from 2 to 10 milligrams of iodine per millilitre $(\mathrm{mg} \mathrm{I} / \mathrm{mL})$ and one control test tube with saline were inserted in a water-filled standard CT performance phantom [22]. The solutions were prepared by diluting a stock solution of $320 \mathrm{mg} \mathrm{I} / \mathrm{mL}$ iodixanol (Visipaque 320, GE Healthcare, Cork, Ireland) with saline ( $\mathrm{NaCl} 0.9 \%$, Baxter SA, Lessines, Belgium). The phantom was examined at 120 and $80 \mathrm{kVp}$ with a constant radiation dose $\left(\mathrm{CTDI}_{\mathrm{vol}}=10.8 \mathrm{mGy}\right)$. All remaining imaging parameters were kept constant: $0.7 \mathrm{~s}$ tube rotation time, 1.375 pitch, $40 \mathrm{~mm}$ beam collimation and $23 \mathrm{~cm}$ field of view. Projection data were reconstructed with standard FBP and a hybrid (ASiR, in this study at a level of $60 \%$ throughout) and full IR methodology (Veo). For ASiR, the $60 \%$ blending level was chosen on the basis of findings from previous studies [18-21] and our clinical experience. For each combination of tube voltage and reconstruction, the $\mathrm{CT}$ value (HU) and noise (SD) were measured in each test tube with a circular region of interest (ROI) of $8 \mathrm{~mm}$ diameter. The contrast to noise ratio (CNR) was calculated by dividing the difference in $\mathrm{CT}$ value of the contrast tube and saline tube by the noise (SD) in the saline tube.

\section{Porcine model}

Three female Göttingen minipigs (Ellegaard, Denmark) with mean age of 518 days (range 490-541) and mean weight of $40.9 \mathrm{~kg}$ (range 38.7-42.9) were included. Study approval was granted by the institutional animal care committee. Port-a-cath units (Power PAC II, $1.9 \mathrm{~mm}$, Smiths Medical, Belgium) were placed at the level of the left shoulder and connected to the vena cava superior. The mean effective abdominal diameter was $29 \pm 3 \mathrm{~cm}$, which corresponds well to the average 18 -yearold human (diameter of $29.2 \mathrm{~cm}$ [23]). The pigs were scanned during a 4-month period with an inter-scan delay of at least $72 \mathrm{~h}$ so as to avoid iodine retention bias. Anaesthesia was induced by an intramuscular injection of $500 \mathrm{mg}$ Zoletil-100, $6.25 \mathrm{mg}$ Rompun, $1.25 \mathrm{~mL}$ ketamine and $2.5 \mathrm{~mL}$ Dolorex at a dose of $0.05 \mathrm{~mL} / \mathrm{kg}$.

\section{Contrast injection and CT protocol}

From standard $320 \mathrm{mg} \mathrm{I} / \mathrm{mL}$ contrast concentration, four further formulations were prepared with saline to achieve concentrations of 120, 170, 220 and $270 \mathrm{mg} \mathrm{I} / \mathrm{mL}$. Contrast was administered at controlled room temperature into the porta-cath unit via a dual head power injector (Nemoto-Kyorindo, Tokyo, Japan). Contrast injection parameters were kept constant (Table 1) and injection was followed by a $20-\mathrm{mL}$ saline chaser. Scan delay times were $40 \mathrm{~s}$ for the hepatic-arterial phase and $60 \mathrm{~s}$ for the portal venous phase. The pigs were 
Table 1 Technical scan parameters and injection protocol of porcine model

\begin{tabular}{lll}
\hline Parameter & $\begin{array}{l}\text { Reference } \\
\text { protocol }\end{array}$ & Study protocols \\
\hline Tube voltage & $120 \mathrm{kVp}$ & $80 \mathrm{kVp}$ \\
Noise index & 30 & $31-37.5$ \\
Helical scan mode & $64 \times 0.625$ & $64 \times 0.625$ \\
Slice thickness and increment & 2.5 & 2.5 \\
$\quad(\mathrm{~mm})$ & 1.375 & 1.375 \\
Pitch & 0.7 & 0.7 \\
Tube rotation time (s) & $\mathrm{FBP}$ & $\mathrm{FBP}, \mathrm{ASiR}-60 \%, \mathrm{Veo}$ \\
Image reconstruction model & 320 & $270,220,170,120$ \\
Contrast agent concentration & & \\
$\quad(\mathrm{mg}$ I/mL) & 2 & 2 \\
Injection rate (mL/s) & 2 & 2 \\
Injection volume (mL/kg) & 0.64 & $0.54,0.44,0.34,0.30$ \\
Iodine delivery rate $(\mathrm{g} \mathrm{I} / \mathrm{s})$ & 640 & $450,440,340,300$ \\
Total iodine dose $(\mathrm{mg} \mathrm{I} / \mathrm{kg})$ & 40,60 & 40,60 \\
\hline Scan delay (s) & &
\end{tabular}

$m g I / m L$ milligrams of iodine per millilitre, $g \mathrm{I} / \mathrm{s}$ grams of iodine per second, $m g \mathrm{I} / \mathrm{kg}$ milligrams of iodine per kilogram of body weight

examined from the liver dome to the pelvic floor. After the topogram of each scan, the noise index (NI) parameter of the automated tube current modulation system was selected in such a way that the projected $\mathrm{CTDI}_{\mathrm{vol}}$ matched the dose of the reference protocol as close as possible. $\mathrm{CTDI}_{\mathrm{vol}}(\mathrm{mGy})$ and DLP (mGy $\mathrm{cm})$ were recorded for each image. Each imaging protocol was repeated three times in randomized sequence, except for the reference protocol that was scanned first in order to obtain a reference $\mathrm{CTDI}_{\mathrm{vol}}$ value as input for subsequent scans.

Quantitative and qualitative image analysis

For quantitative evaluation, the average $\mathrm{CT}$ value and $\mathrm{SD}$ were measured in the abdominal aorta, portal vein, hepatic parenchyma and dorsal muscle by circular ROIs. For the hepatic-arterial phase, the $\mathrm{CT}$ value in the abdominal aorta, $\mathrm{SD}$ value in the unenhanced dorsal muscle and the dose normalized CNR (CNRD) were considered figures of merit for image quality. CNR was calculated as (mean $\mathrm{CT}$ value aorta - mean CT value muscle)/SD muscle. In order to compare the CNR, independent of radiation dose, each obtained CNR value was dose normalized by the Poisson noise model with $\mathrm{SD} \approx\left(\mathrm{CTDI}_{\mathrm{vol}}\right)^{a}$, with exponent $a$ equal to $-0.5[22,24]$. However, a recent study reported a different exponent when the Veo reconstruction is applied [25]. To verify this, we performed additional experiments on one pig to establish the relationship between $\mathrm{SD}$ and $\mathrm{CTDI}_{\mathrm{vol}}$ for FBP, ASiR and Veo reconstructions.
For the portal venous phase the enhancements of both portal vein and hepatic parenchyma were considered. In the portal vein, the $C T$ value was measured and CNRD was calculated in a similar fashion. In the liver parenchyma, the CT value, SD and dose normalized SNR (SNRD) were determined in the posterior segment of the right lobe. SNR was calculated as the ratio between the mean CT value parenchyma and the SD parenchyma. Dose normalization was performed in a similar fashion as with CNRD. In order to appreciate the impact of both radiation dose and contrast dose on image quality, we provide 3D graphs that represent the mean observed CNR and SNR at each tested iodine concentration (120-320 mg I/mL) with a CTDI ${ }_{\mathrm{vol}}$ extrapolation over a range of 1-15 mGy. Interpolation and extrapolation according radiation dose was done by the previously obtained SD versus $\mathrm{CTDI}_{\mathrm{vol}}$ relationship, and B-spline interpolation (Mathlab, The Mathworks, Natick, MA, USA) was used in the contrast concentration direction. Subjective qualitative analysis was performed in the liver parenchymal phase for the reference and $170 \mathrm{mg} \mathrm{I} / \mathrm{mL}, 80 \mathrm{kVp}$ protocols that were scanned with comparable CTDI ${ }_{\text {vol }}$. Two radiologists (K.N., I.W.) with respectively 7 and 10 years of experience in abdominal CT independently performed a qualitative analysis of deidentified $\mathrm{CT}$ images on a clinical workstation. Criteria for image quality evaluation (Table 2) were based on reported abdominal CT quality studies $[10,14]$.

\section{Radiation dose evaluation}

Besides technical dose descriptors, effective dose $(E)$ is considered to estimate the potential dose to a reference human applying the same scan protocols as in this preclinical study. $E$ was estimated following ICRP-103 guidelines [26] by using a CT patient dosimetry calculator (CTDosimetry_1.04, Impactscan.org) for a standard abdomen scan of $50 \mathrm{~cm}$ from the liver dome to the pelvic floor.

Table 2 Qualitative image analysis by expert reading

\begin{tabular}{l} 
Parameter $\quad$ Score \\
\hline $\begin{array}{r}\text { Overall perceived quality } \\
1=\text { very poor; } 2=\text { suboptimal; } 3=\text { acceptable; } 4=\text { above } \\
\text { average; } 5=\text { excellent }\end{array}$ \\
$\begin{array}{r}\text { Enhancement of organs } \\
1=\text { very poor; } 2=\text { suboptimal; } 3=\text { acceptable; } 4=\text { above } \\
\text { average; } 5=\text { excellent }\end{array}$ \\
$\begin{array}{r}\text { Image noise } \quad \text { unacceptably high; } 2=\text { higher than average; } 3=\text { average; } \\
4=\text { less than average; } 5=\text { minimum noise }\end{array}$ \\
$\begin{array}{r}\text { Streak and beam hardening artefacts } \\
1=\end{array}$ \\
impajor impairing further evaluation; $2=$ major without
\end{tabular}


Statistical analysis

Data were analysed using available software (SPSS, version 14; SPSS, Chicago, Ill). The impact of reconstruction method on $\mathrm{CT}$ values in the phantom model was analysed by linear regression. Quantitative image quality parameters of the porcine study and reference protocols were compared using a nonparametric Mann-Whitney $U$ test. A Chi square test was used to investigate differences in the qualitative scores recorded by the two radiologists. For all comparisons, the statistical significance level was set at 0.05 . Unless otherwise indicated, all reported data are median values with $95 \%$ confidence intervals $(\mathrm{CI})$.

\section{Results}

Phantom study

CT values showed a linear response as a function of iodine concentration (Fig. 1) and there was no significant difference between reconstruction methods (Pearson correlation 1.00, $p<0.001)$. Lower $\mathrm{kVp}$ resulted in higher $\mathrm{CT}$ values $(1.65-$ fold) as demonstrated by the increased slope of the curve. At $80 \mathrm{kVp}$ the iodine concentration fraction that results in equal CT value compared to $120 \mathrm{kVp}$ is about $60 \%$. The CNR increases more rapidly, caused by the combined effect of higher CT values and noise reduction due to both IR algorithms. At $80 \mathrm{kVp}$, the iodine concentration fraction that results in equal CNR compared to $120 \mathrm{kVp}-\mathrm{FBP}$ is about $50 \%$ when using ASiR and about $45 \%$ when using Veo.

\section{Porcine model}

Compared to the $(120 \mathrm{kVp}, 320 \mathrm{mg} \mathrm{I} / \mathrm{mL})$ reference protocol, the $(80 \mathrm{kVp}, 270 \mathrm{mg} \mathrm{I} / \mathrm{mL})$ study protocol resulted in higher CT values in the abdominal aorta (Fig. 2, Table 3). There was no significant difference with the next lower concentrations 220 and $170 \mathrm{mg} \mathrm{I} / \mathrm{mL}$, whereas a concentration of $120 \mathrm{mg}$ $\mathrm{I} / \mathrm{mL}$ yielded inferior enhancement. In liver parenchyma during the portal venous phase, both study protocols with 270 and
$220 \mathrm{mg} \mathrm{I} / \mathrm{mL}$ resulted in higher CT values, and $120 \mathrm{mg} \mathrm{I} / \mathrm{mL}$ yielded inferior enhancement. This was also observed for the portal vein. The median $\mathrm{CTDI}_{\mathrm{vol}}$ of the reference protocol scans was 7.8 mGy (CI 6.8-8.4 mGy). Hence, we dose normalized all noise values to a reference of $8.0 \mathrm{mGy}$ and employed this to calculate CNRD and SNRD data (Fig. 3, Table 3). From the noise versus dose regression analysis, the following exponents were observed for FBP ( $a=-0.498$ with $\left.r^{2}=0.96\right), \operatorname{ASiR}\left(a=-0.508\right.$ with $\left.r^{2}=0.95\right)$ and Veo $(a=$ -0.232 with $\left.r^{2}=0.94\right)$. Consequently, dose normalization was performed for FBP and ASiR with $a=-0.50$, as in the experimentally confirmed model, and for Veo with $a=-0.23$.

In the abdominal aorta, all study protocols with ASiR reconstruction, apart from $120 \mathrm{mg} \mathrm{I} / \mathrm{mL}$, resulted in higher or non-inferior CNRD values. Owing to their increased noise suppression, all Veo protocols resulted in markedly higher image quality. The same trend was observed for the portal vein. In the liver parenchyma, all study protocols resulted in higher SNRD values for both ASiR and Veo reconstruction. With all ASiR study protocols, soft tissue noise in the dorsal muscle was comparable (SD range 14.8-20.8) to that in the reference protocol (SD 17.9). Veo reconstruction significantly reduced soft tissue noise values (SD range 9.0-11.3).

The improved image quality with the study protocols allows flexibility in the trade-off between radiation dose and contrast agent dose (Fig. 4). Every combination above the isoCNR (arterial phase) or isoSNR (parenchymal phase) lines allows improved image quality in terms of CNR and SNR respectively. In the arterial phase, a concentration of $170 \mathrm{mg} \mathrm{I} / \mathrm{mL}$ yields equal $\mathrm{CNR}$ at a dose of $7.6 \mathrm{mGy}$ with ASiR. With Veo, the radiation dose can be decreased to $0.6 \mathrm{mGy}$ for this concentration. In the liver parenchymal phase, a concentration of $170 \mathrm{mg} \mathrm{I} / \mathrm{mL}$ already yields equal SNR at a dose of $4.4 \mathrm{mGy}$ with ASIR and $0.12 \mathrm{mGy}$ with Veo.

For subjective image quality, three $80 \mathrm{kVp}, 170 \mathrm{mg} \mathrm{I} / \mathrm{mL}$ study protocol scans with median $\mathrm{CTDI}_{\mathrm{vol}}$ of $7.1 \mathrm{mGy}$ were considered (Table 4, Fig. 5). Compared to the reference, no difference in subjective image quality parameters was observed with the $80 \mathrm{kVp}, 170 \mathrm{mg} \mathrm{I} / \mathrm{mL}$ study protocol for ASiR reconstruction (Table 4, Fig. 5). All scans were of at least
Fig. 1 Mean CT value (a) and contrast to noise ratio (b) as a function of iodine concentration for FBP at $120 \mathrm{kVp}$ and both $\mathrm{ASiR}$ and $\mathrm{Veo}$ at $80 \mathrm{kVp}$, obtained from phantom data. Error bars represent $95 \%$ confidence intervals
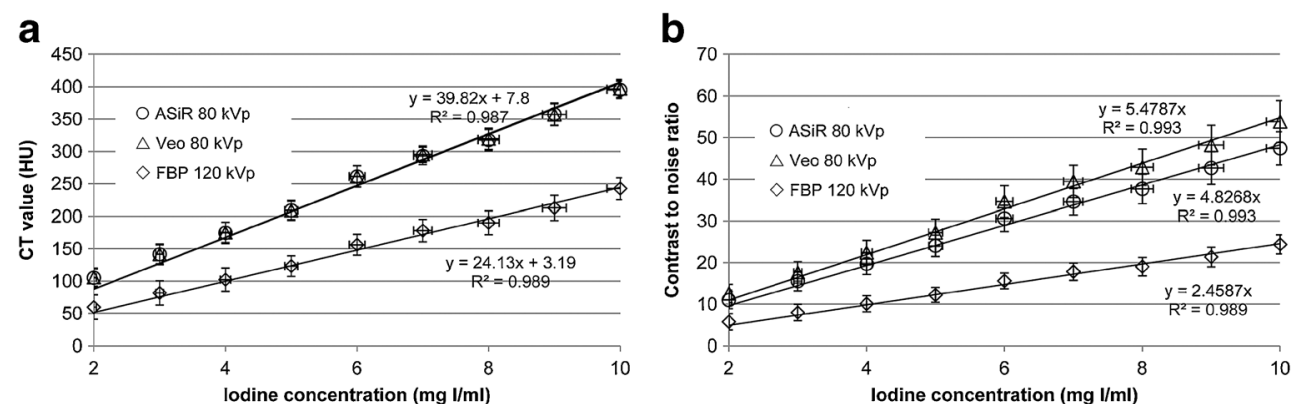
a

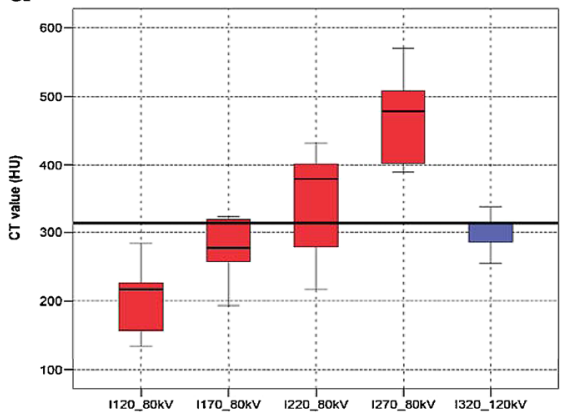

b

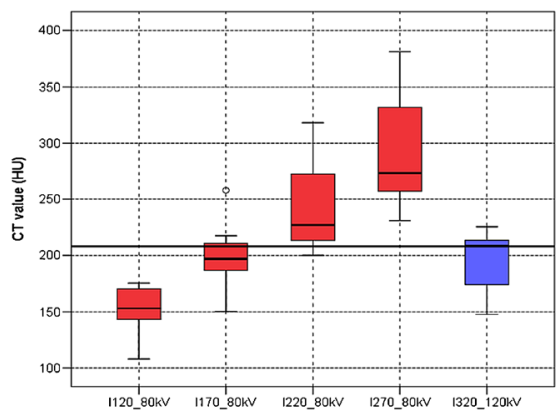

C



Fig. 2 Box and whisker plots of CT enhancement in abdominal aorta (a), portal vein (b) and liver parenchyma (c). Each protocol is labeled by its combination of iodine concentration (I from 120 to $320 \mathrm{mg} \mathrm{I} / \mathrm{mL}$ ) and tube voltage ( 80 or $120 \mathrm{kVp}$ ). The solid line in the box represents the median value and the upper and lower bars represent the first and third quartiles respectively, whiskers represent the $95 \%$ confidence interval. The bold reference line in the graph represents the median value of the reference protocol acceptable quality. With Veo reconstruction, overall quality was rated better than reference (3.3 compared to 2.7 ) and in particular image noise was perceived to be less present $(4.3$ compared to 2.5).

\section{Radiation dose}

For the $120 \mathrm{kVp}$ and $80 \mathrm{kVp}$ protocols, the $\mathrm{CTDI}_{\mathrm{vol}}$ to $E$ conversion factors are estimated to be 0.80 and $0.69 \mathrm{mSv} / \mathrm{mGy}$ respectively, in case of a $50-\mathrm{cm}$ abdomen scan from the liver dome to the pelvic floor of a reference human.

\section{Discussion}

From the point of patient safety, the amount of iodine dose and radiation dose should be minimized to a level still providing sufficiently diagnostic images $[1,27,28]$. We found that in a porcine model for abdominal $\mathrm{CT}$, both contrast agent and radiation dose can be significantly decreased by combining low tube voltage $(80 \mathrm{kVp})$ imaging with iterative reconstruction while maintaining good image quality. Previous reports, based on standard CT techniques prior to iterative reconstruction, suggested that a total iodine dose of about $500-600 \mathrm{mg}$ of iodine per kilogram of body weight is required to obtain

Table 3 Quantitative image quality metrics

\begin{tabular}{|c|c|c|c|c|c|c|c|}
\hline \multirow[t]{2}{*}{ Protocol } & \multicolumn{3}{|l|}{ Abdominal aorta } & \multicolumn{2}{|l|}{ Portal vein } & \multicolumn{2}{|l|}{ Liver parenchyma } \\
\hline & CT value (HU) & $\mathrm{CNR}$ at $8 \mathrm{mGy}$ & Noise (SD) at $8 \mathrm{mGy}$ & $\mathrm{CT}$ value (HU) & $\mathrm{CNR}$ at $8 \mathrm{mGy}$ & $\mathrm{CT}$ value (HU) & SNR at $8 \mathrm{mGy}$ \\
\hline \multicolumn{8}{|c|}{ Reference protocol at $120 \mathrm{kVp}$} \\
\hline $\begin{array}{l}320 \mathrm{mg} \mathrm{I} / \mathrm{mL} \\
\text { FBP }\end{array}$ & $314(284-325)$ & $13.7(12.8-15.9)$ & $17.9(16.4-19.4)$ & $208(177-217)$ & $8.5(6.8-9.1)$ & $115(111-121)$ & $5.6(5.2-5.9)$ \\
\hline \multicolumn{8}{|c|}{ Study protocols at $80 \mathrm{kVp}$} \\
\hline $\begin{array}{l}270 \mathrm{mg} \mathrm{I} / \mathrm{mL} \\
\mathrm{ASiR}\end{array}$ & $468 *(377-561)$ & $28 *(22.8-31.9)$ & $16.3(6.6-38.9)$ & $273 *(219-369)$ & $14.2 *(11.5-19.2)$ & $146^{*}(118-178)$ & $10.3 *(8.5-11.5)$ \\
\hline $\begin{array}{l}270 \mathrm{mg} \mathrm{I} / \mathrm{mL} \\
\text { Veo }\end{array}$ & $489 *(381-583)$ & $48.7 *(44.1-52.7)$ & $10.9 *(5.9-16.6)$ & $266 *(220-381)$ & $27.1 *(22.8-30.8)$ & $155^{*}(118-185)$ & $17.3 *(13.1-20.2)$ \\
\hline $\begin{array}{l}220 \mathrm{mg} \mathrm{I} / \mathrm{mL} \\
\text { ASiR }\end{array}$ & $382(291-405)$ & $22.3 *(17.5-24.5)$ & $20.8 *(19-31.9)$ & $226 *(210-272)$ & $12.3 *(11.2-15.1)$ & $132 *(126-143)$ & $8.9 *(7.6-9.8)$ \\
\hline $\begin{array}{l}220 \mathrm{mg} \mathrm{I} / \mathrm{mL} \\
\text { Veo }\end{array}$ & $380(296-410)$ & $42.1 *(31.7-48)$ & $11.3 *(9.4-13.4)$ & $226 *(213-276)$ & $23.3 *(20.1-29.9)$ & $131 *(127-149)$ & $15.5^{*}(14.6-17.7)$ \\
\hline $\begin{array}{l}170 \mathrm{mg} \mathrm{I} / \mathrm{mL} \\
\mathrm{ASiR}\end{array}$ & $278(235-312)$ & $15(12.2-17)$ & $16.1(12.4-33)$ & $197(175-221)$ & $10(7.7-11.4)$ & $122(115-129)$ & $7.5 *(6.4-8.7)$ \\
\hline $\begin{array}{l}170 \mathrm{mg} \mathrm{I} / \mathrm{mL} \\
\text { Veo }\end{array}$ & $279(235-316)$ & $24.9 *(20.5-31.4)$ & $9.1 *(7.5-15)$ & $205(189-224)$ & $16.7 *(15.2-19.9)$ & $122(114-130)$ & $15^{*}(12.3-16.7)$ \\
\hline $\begin{array}{l}120 \mathrm{mg} \mathrm{I} / \mathrm{mL} \\
\mathrm{ASiR}\end{array}$ & $216^{*}(168-246)$ & $11.7 *(8-14.6)$ & $14.8(11.5-25.6)$ & $152 *(135-168)$ & $7(5.7-8.3)$ & $111 *(105-113)$ & $7.1 *(6.5-7.7)$ \\
\hline $\begin{array}{l}120 \mathrm{mg} \mathrm{I} / \mathrm{mL} \\
\text { Veo }\end{array}$ & $223 *(171-242)$ & $17.9(14-23.1)$ & $9.0 *(7.5-12)$ & $147 *(140-171)$ & $12.4 *(10-13.9)$ & $113(106-116)$ & $13.6^{*}(12.6-14.1)$ \\
\hline
\end{tabular}

Data are medians with $95 \%$ confidence interval between brackets

* Indicates significant difference compared to reference protocol $(p<0.05)$ 
a

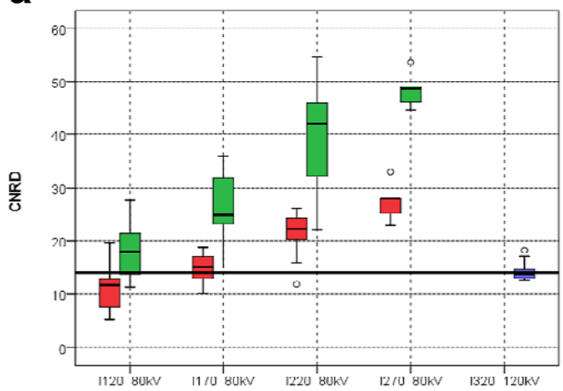

b

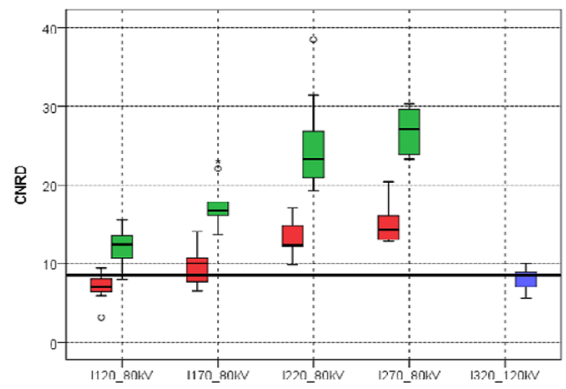

C

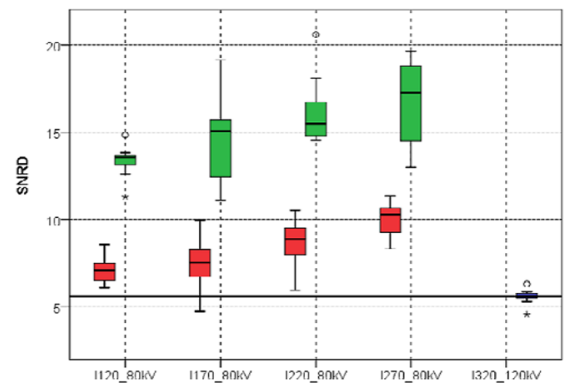

Fig. 3 Box and whisker plots of radiation dose normalized quantitative image quality (CNRD and SNRD) in abdominal aorta (a), portal vein (b) and liver parenchyma (c) with ASiR (red boxes) and Veo (green boxes) reconstruction. Each protocol is indicated by its combination of iodine concentration (I from 120 to $320 \mathrm{mg} \mathrm{I} / \mathrm{mL}$ ) and tube voltage (80 or
$120 \mathrm{kVp}$ ). The solid line in the box represents the median value and the upper and lower bars represent the first and third quartiles respectively, whiskers represent the $95 \%$ confidence interval. The bold reference line in the graph represents the median value of the reference protocol

authors added hybrid iterative reconstruction and were able to reduce the radiation dose further to $11.1 \mathrm{mGy}$. Our results confirm the benefit of adding iterative reconstruction to low tube voltage $\mathrm{CT}$, but also suggest that larger contrast agent and radiation dose reductions might be possible. With $\mathrm{ASiR}$, the use of $340 \mathrm{mg} \mathrm{I} / \mathrm{kg}(170 \mathrm{mg} \mathrm{I} / \mathrm{mL})$ would still allow $5 \%$ radiation dose (7.6 mGy) reduction in the arterial phase, a $29 \%$ reduction $(5.7 \mathrm{mGy})$ for the portal vein and $45 \%$ reduction (4.4 mGy) for the liver parenchyma. The practical implication of this observation is that patients could be scanned with a lower radiation dose during the portal venous phase compared to the arterial phase by adjusting the automatic exposure control system. When Veo reconstruction is standard FBP reconstruction. In a second study [9], the same

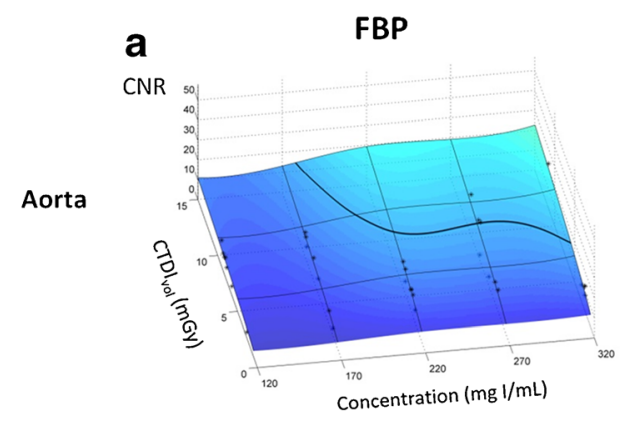

d

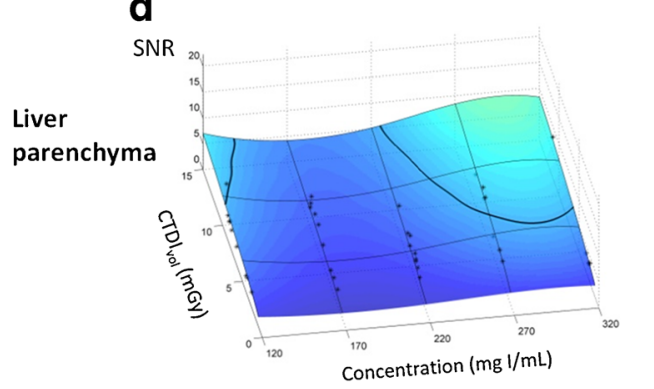

e

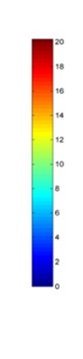

b

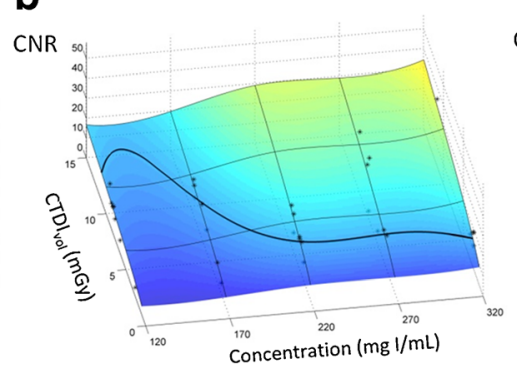

e

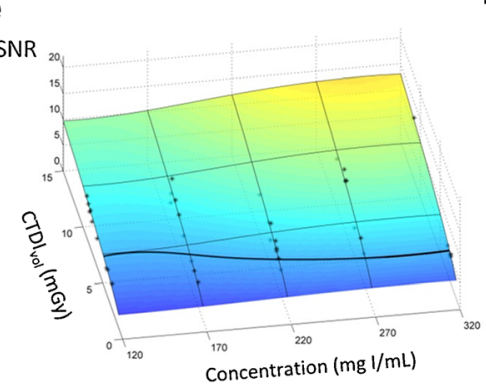

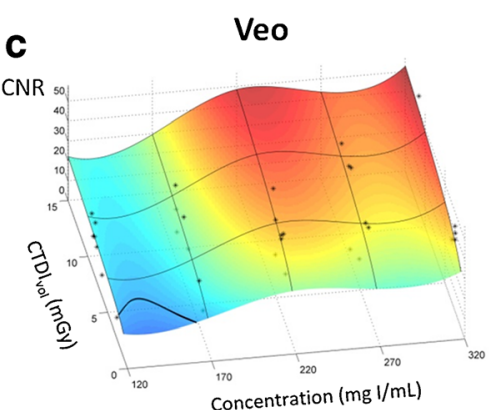

f

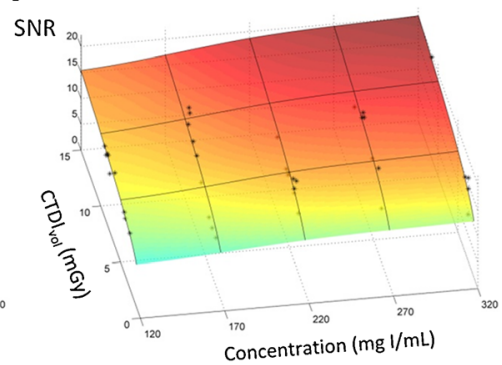

Fig. 4 Colour-coded 3D surface plots of the CNR and SNR from the 80$\mathrm{kVp}$ study protocols for the abdominal aorta in the hepato-arterial phase $(\mathbf{a}-\mathbf{c})$ and the liver parenchyma in the portal phase $(\mathbf{d}-\mathbf{f})$. For each structure, the results for $\operatorname{FBP}(\mathbf{a}, \mathbf{d}), \operatorname{ASiR}(\mathbf{b}, \mathbf{e})$ and $\operatorname{Veo}(\mathbf{c}, \mathbf{f})$ reconstruction are shown. Each data point is represented by an asterisk.
The solid curved line in each graph represents the observed CNR (13.7) and SNR (5.6) values of the reference protocol extrapolated to a CTDI $\mathrm{vol}_{\mathrm{vol}}$ of $8.0 \mathrm{mGy}$. Any radiation-concentration combination above that line yields improved image quality compared to the reference protocol 
Table 4 Image quality scores for the reference protocol and $80 \mathrm{kVp}$, $170 \mathrm{mg} \mathrm{I} / \mathrm{mL}$ study protocol

\begin{tabular}{|c|c|c|c|}
\hline \multirow{3}{*}{$\begin{array}{l}\text { Median and range } \\
\text { CTDI }_{\mathrm{vol}} \\
\text { Reconstruction }\end{array}$} & \multicolumn{3}{|l|}{ Protocol } \\
\hline & \multirow{2}{*}{$\begin{array}{l}120 \mathrm{kVp}, 320 \mathrm{mg} \mathrm{I} / \mathrm{mL} \\
7.8(6.3-9.2) \mathrm{mGy} \\
\text { FBP }\end{array}$} & \multicolumn{2}{|c|}{$\begin{array}{l}80 \mathrm{kVp}, 170 \mathrm{mg} \mathrm{I} / \mathrm{mL} \\
7.1(5.9-9.2) \mathrm{mGy}\end{array}$} \\
\hline & & ASiR & Veo \\
\hline $\begin{array}{l}\text { Overall perceived } \\
\text { quality }(1-5)\end{array}$ & 2.7 & 2.5 & $3.3^{*}$ \\
\hline $\begin{array}{l}\text { Enhancement of } \\
\text { abdominal organs } \\
(1-5)\end{array}$ & 2.8 & 2.8 & 3.3 \\
\hline Image noise (1-5) & 2.5 & 2.7 & $4.3^{*}$ \\
\hline Artefacts $(1-4)$ & 2.8 & 2.8 & 2.8 \\
\hline
\end{tabular}

* Indicates significant difference compared to reference protocol $(p<0.05)$

used, radiation doses can even be decreased further. With a single phase of the reference protocol $\left(\mathrm{CTDI}_{\mathrm{vol}}=7.8 \mathrm{mGy}\right.$, $\mathrm{DLP}=390 \mathrm{mGy} \mathrm{cm}$ ), the estimated effective dose to a human would be $6.2 \mathrm{mSv}$. A $170 \mathrm{mg} \mathrm{I} / \mathrm{mL}$ study protocol with ASiR $\left(\mathrm{CTDI}_{\mathrm{vol}}=7.6 \mathrm{mGy}, \mathrm{DLP}=380 \mathrm{mGy} \mathrm{cm}\right)$ for equal arterial enhancement would result in an effective dose of $5.2 \mathrm{mSv}$ (16\% reduction). For equal parenchymal enhancement, radiation dose could be decreased to $\mathrm{CTDI}_{\mathrm{vol}}=4.4 \mathrm{mGy}$, resulting in an $E=3.5 \mathrm{mSv}$ ( $34 \%$ reduction).

In agreement with reported data [1,31], parenchymal enhancement was observed to be less affected by iodine concentration. Whereas arterial CNR strongly depends on contrast media concentration and radiation dose, liver SNR is primarily dominated by radiation dose for the range of concentrations tested in this study. With the exception of liver parenchyma enhancement, inferior CT values were observed when the lowest concentration of $120 \mathrm{mg} \mathrm{I} / \mathrm{mL}$ was injected: CT values dropped significantly in the aorta (from 314 to $216 \mathrm{HU}$ ) and portal vein (from 208 to $152 \mathrm{HU}$ ), but remained about the same in the liver (from 115 to $111 \mathrm{HU}$ ). However, in the venous phase, the CNRD and SNRD were respectively not different and higher compared to the reference.

The porcine model demonstrated a higher contrast enhancement than initially suggested by our phantom. The relative 1.65 -fold increase of CT value in the phantom data suggests that an approximately $190 \mathrm{mg} \mathrm{I} / \mathrm{mL}, 80 \mathrm{kVp}$ protocol yields equal enhancement. However in the porcine study, noninferior CT values were observed with a concentration as low as $170 \mathrm{mg} \mathrm{I} / \mathrm{mL}$. This observation suggests that, in contrast to static phantom data, the relationship between iodine concentration and enhancement is not strictly linear and that other properties come into play. A possible explanation is that reduced iodine concentration may be more physiological and distribute more easily and more evenly in the vessels, resulting in improved enhancement particularly in the early phase [32].

Some limitations of our study merit consideration. First, although swine serve as good models [33], the acquired results cannot be automatically translated to humans. Our model suggests that equal results could be expected for patients
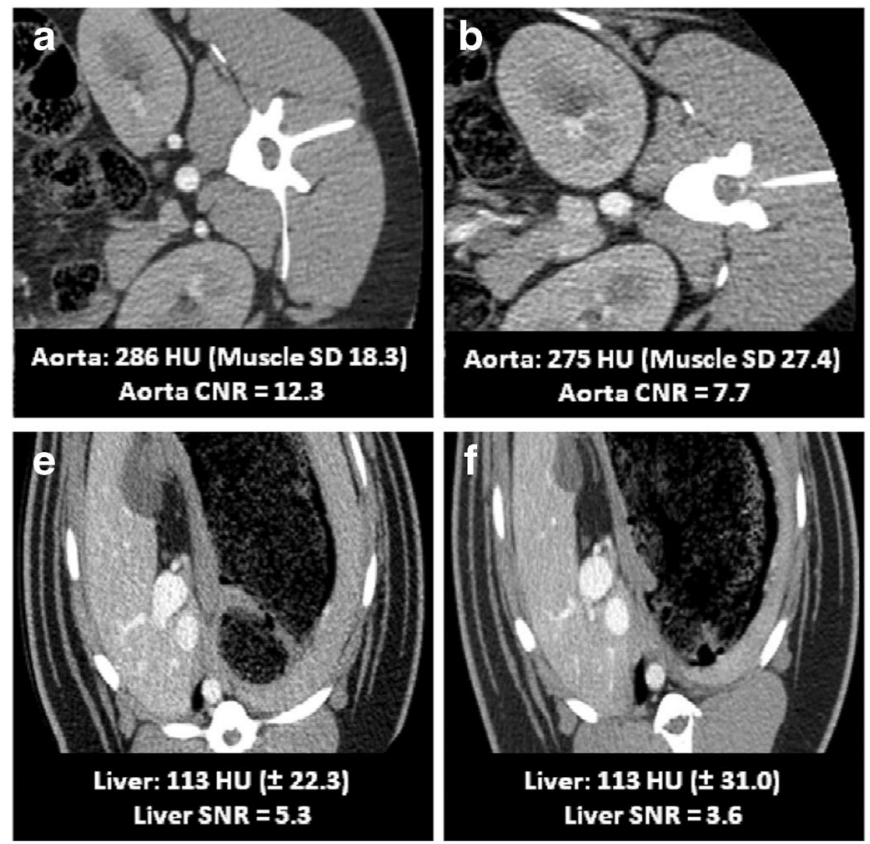

Fig. $5120 \mathrm{kVp}, 320 \mathrm{mg} \mathrm{I} / \mathrm{mL}$ reference protocol compared to $80 \mathrm{kVp}$, $170 \mathrm{mg} \mathrm{I} / \mathrm{mL}$ study protocol. a Arterial and e venous phase images obtained with the reference protocol of $120 \mathrm{kVp}, 320 \mathrm{mg} \mathrm{I} / \mathrm{mL}$, $\mathrm{CTDI}_{\mathrm{vol}}=7.2 \mathrm{mGy}$ and FBP reconstruction. b-d Arterial and $\mathbf{f}, \mathbf{g}$ venous phase images obtained with a study protocol of $80 \mathrm{kVp}$,
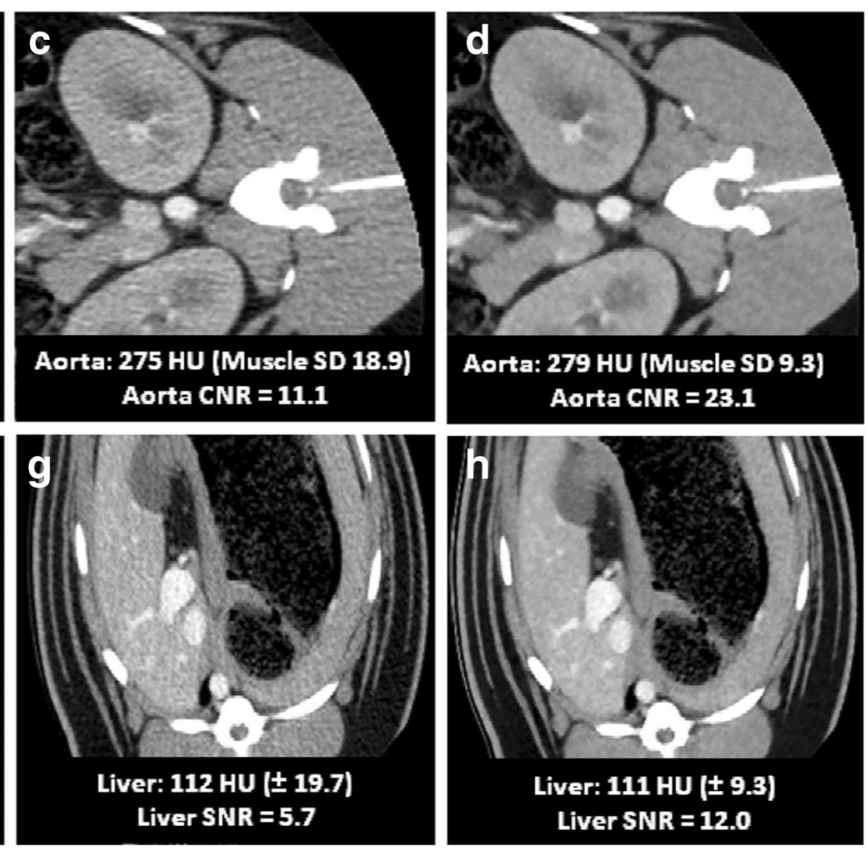

$170 \mathrm{mg} \mathrm{I} / \mathrm{mL}, \mathrm{CTDI}_{\mathrm{vol}}=5.9 \mathrm{mGy}$ and $\mathrm{FBP}(\mathbf{b}, \mathbf{f})$ reconstruction, ASiR $(\mathbf{c}, \mathbf{g})$ reconstruction and Veo $(\mathbf{d}, \mathbf{h})$ reconstruction. Recorded CT values, noise, CNR and SNR are shown on each image. Note the reduced quality of the $80-\mathrm{kVp}$ FBP images $(\mathbf{b}, \mathbf{f})$, which is restored by ASiR $(\mathbf{c}, \mathbf{g})$ and Veo $(\mathbf{d}, \mathbf{h})$ reconstruction 
having an effective abdominal diameter of around $30 \mathrm{~cm}$. Larger-sized patients generally require higher tube voltage settings which may limit any contrast media dose reduction. Conversely, slimmer patients would allow further dose reductions and might also benefit from even lower tube voltages, e.g. $70 \mathrm{kVp}$. Second, we only assessed one type of scanner with two types of iterative reconstruction. Different ASiR blending levels other than $60 \%$, or other imaging systems with their specific reconstruction packages, might present different results, although the same trend can be expected. The amount of ASiR blending in our study is at the high end of the clinical range, which is typically reported to be from 30 to $70 \%[15,18-21]$. Although studies demonstrate no loss in diagnostic confidence at blends of $60 \%$ or higher [18, 20,21], most authors still advocate a lower blend considering the subjective feel of the image and reported comfort level of the radiologist [34]. With $\mathrm{ASiR}$, image noise in terms of standard deviation demonstrates a linear decrease as a function of percentage blending level $[16,34]$. Thus, the selection of a level below $60 \%$ will require a higher radiation dose setting for images of an equal amount of noise. Third, the results cannot be automatically translated to indications such as cardiovascular disease, detection of pancreatic tumours or liver lesions. Although image quality in our study was considered to be at least acceptable, liver lesion conspicuity can be hampered by blotchy image appearance that can be associated with iterative reconstruction at low radiation doses [18].

Our results illustrate the increasing complexity of contrast media administration with the available and continuously evolving CT technology. Formulations for use with advanced CT technology could contribute to the improvement of patient care and to the practice of personalized medicine in radiology.

In conclusion, iterative reconstruction has a major, positive impact on the balance between image quality, contrast dose and radiation dose. We found that in a porcine model, the combination of an $80-\mathrm{kVp}$ technique with iterative reconstruction allowed a $47 \%$ contrast dose and $16 \%$ radiation dose reduction compared to a standard $120-\mathrm{kVp}$ scan with FBP reconstruction for images of comparable quality. Full iterative reconstruction techniques allow even further dose reductions. Confirmation in humans is recommended before implementing our technique in the clinical setting.

Acknowledgments The scientific guarantor of this publication is Prof. $\mathrm{J}$ de Mey. The authors of this manuscript declare relationships with the following companies: GE Healthcare. This study has received funding by GE Healthcare, Medical Diagnostics. One of the authors has significant statistical expertise. No complex statistical methods were necessary for this paper. Institutional review board approval was obtained. Approval from the institutional animal care committee was obtained. Some study subjects or cohorts have been previously reported in Buls N, Van Gompel G, Nieboer K, Van Cauteren T, Willekens I, de Mey J. Reduction of iodine concentration in CT angiography (CTA) by a combined use of low
$\mathrm{kVp}$ and iterative reconstruction: feasibility study on a porcine model. European Congress of Radiology, 1-5 March 2012, Vienna, Austria

Methodology: prospective, experimental, performed at one institution.

Open Access This article is distributed under the terms of the Creative Commons Attribution Noncommercial License which permits any noncommercial use, distribution, and reproduction in any medium, provided the original author(s) and the source are credited.

\section{References}

1. Bae KT (2010) Intravenous contrast medium administration and scan timing at CT: considerations and approaches. Radiology 256:32-61

2. Nakaura T, Awai K, Maruyama N et al (2011) Abdominal dynamic $\mathrm{CT}$ in patients with renal dysfunction: contrast agent dose reduction with low tube voltage and high tube current-time product settings at 256-detector row CT. Radiology 261:467-476

3. Nakayama Y, Awai K, Funama Y et al (2005) Abdominal CT with low tube voltage: preliminary observations about radiation dose, contrast enhancement, image quality, and noise. Radiology 237: 945-951

4. Waaijer A, Prokop M, Velthuis BK et al (2007) Circle of Willis at CT angiography: dose reduction and image quality-reducing tube voltage and increasing tube current settings. Radiology 242: 832-839

5. Marin D, Nelson RC, Barnhart H et al (2010) Detection of pancreatic tumors, image quality, and radiation dose during the pancreatic parenchymal phase: effect of a low-tube-voltage, high-tube-current CT technique-preliminary results. Radiology 256:450-459

6. Schindera ST, Nelson RC, Mukundan S Jr et al (2008) Hypervascular liver tumors: low tube voltage, high tube current multi-detector row CT for enhanced detection-phantom study. Radiology 246:125-132

7. Sigal-Cinqualbre AB, Hennequin R, Abada HT, Chen X, Paul JF (2004) Low-kilovoltage multi-detector row chest CT in adults: feasibility and effect on image quality and iodine dose. Radiology 231: 169-174

8. Hunsaker AR, Oliva IB, Cai T et al (2010) Contrast opacification using a reduced volume of iodinated contrast material and low peak kilovoltage in pulmonary $\mathrm{CT}$ angiography: objective and subjective evaluation. AJR Am J Roentgenol 195:W118-W124

9. Nakaura T, Nakamura S, Maruyama N et al (2012) Low contrast agent and radiation dose protocol for hepatic dynamic CT of thin adults at 256-detector row CT: effect of low tube voltage and hybrid iterative reconstruction algorithm on image quality. Radiology 264 : 445-454

10. Utsunomiya D, Oda S, Funama Y et al (2010) Comparison of standard- and low-tube voltage MDCT angiography in patients with peripheral arterial disease. Eur Radiol 20:2758-2765

11. Cho ES, Chung TS, Oh DK, Choi HS, Suh SH, Lee HK et al (2012) Cerebral computed tomography angiography using a low tube voltage $(80 \mathrm{kVp})$ and a moderate concentration of iodine contrast material: a quantitative and qualitative comparison with conventional computed tomography angiography. Invest Radiol 47:142-147

12. Papadakis AE, Perisinakis K, Raissaki M, Damilakis J (2013) Effect of $\mathrm{x}$-ray tube parameters and iodine concentration on image quality and radiation dose in cerebral pediatric and adult CT angiography: a phantom study. Invest Radiol 48:192-199

13. Szucs-Farkas Z, Verdun FR, von Allmen G, Mini RL, Vock P (2008) Effect of X-ray tube parameters, iodine concentration, and patient size on image quality in pulmonary computed tomography angiography: a chest-phantom-study. Invest Radiol 43:374-381

14. Kalra MK, Woisetschläger M, Dahlström N et al (2012) Radiation dose reduction with sinogram affirmed iterative reconstruction 
technique for abdominal computed tomography. J Comput Assist Tomogr 36:339-346

15. Willemink MJ, Leiner T, de Jong PA, de Heer LM, Nievelstein RA, Schilham AM et al (2013) Iterative reconstruction techniques for computed tomography part 2: initial results in dose reduction and image quality. Eur Radiol 23:1632-1642

16. Hara AK, Paden RG, Silva AC, Kujak JL, Lawder HJ, Pavlicek W (2009) Iterative reconstruction technique for reducing body radiation dose at CT: feasibility study. AJR Am J Roentgenol 193:764-771

17. Marin D, Nelson RC, Schindera ST, Richard S, Youngblood RS, Yoshizumi TT et al (2010) Low-tube-voltage, high-tube-current multidetector abdominal CT: improved image quality and decreased radiation dose with adaptive statistical iterative reconstruction algorithm-initial clinical experience. Radiology 254:145-153

18. Singh S, Kalra MK, Hsieh J, Licato PE, Do S, Pien HH et al (2010) Abdominal CT: comparison of adaptive statistical iterative and filtered back projection reconstruction techniques. Radiology 257:373-383

19. Katsura M, Matsuda I, Akahane M et al (2013) Model-based iterative reconstruction technique for ultralow-dose chest CT: comparison of pulmonary nodule detectability with the adaptive statistical iterative reconstruction technique. Invest Radiol 48:206-212

20. McLaughlin PD, Murphy KP, Hayes SA et al (2014) Non-contrast $\mathrm{CT}$ at comparable dose to an abdominal radiograph in patients with acute renal colic; impact of iterative reconstruction on image quality and diagnostic performance. Insights Imaging 5:217-230

21. Flicek KT, Hara AK, Silva AC, Wu Q, Peter MB, Johnson CD (2010) Reducing the radiation dose for CT colonography using adaptive statistical iterative reconstruction: a pilot study. Am J Roentgenol 195:126-131

22. Cacak R, Gray J, Hangartner T, Hendrick R, Rossi R (1993) Specification and acceptance testing of computed tomography scanners. Report of AAPM Task Group 39. American Association of Physicists in Medicine, College Park

23. Boone J, Strauss K, Cody D et al (2011) Size-specific dose estimates (SSDE) in pediatric and adult body CT examinations. Report of AAPM Task Group 204. American Association of Physicists in Medicine, College Park
24. Vollmar SV, Kalender WA (2009) Reduction of dose to the female breast as a result of spectral optimization for high-contrast thoracic CT imaging: a phantom study. Br J Radiol 82:920-929

25. Miéville FA, Gudinchet F, Brunelle F, Bochud FO, Verdun FR (2013) Iterative reconstruction methods in two different MDCT scanners: physical metrics and 4-alternative forced-choice detectability experiments-a phantom approach. Phys Med 29:99-110

26. International Commission on Radiological Protection (2007) 2007 Recommendations of the ICRP. ICRP Publication 103. Ann ICRP $37(2-4)$

27. Brenner DJ, Hall EJ (2007) Computed tomography - an increasing source of radiation exposure. N Engl J Med 357:2277-2284

28. Mathews J, Forsythe AV, Brady Z et al (2013) Cancer risk in 680000 people exposed to computed tomography scans in childhood or adolescence: data linkage study of 11 million Australians. BMJ 346:f2360

29. Yamashita Y, Komohara Y, Takahashi M et al (2000) Abdominal helical CT: evaluation of optimal doses of intravenous contrast material - a prospective randomized study. Radiology 216:718-723

30. Suzuki H, Oshima H, Shiraki N, Ikeya C, Shibamoto Y (2004) Comparison of two contrast materials with different iodine concentrations in enhancing the density of the aorta, portal vein and liver at multi-detector row CT: a randomized study. Eur Radiol 14:2099 2104

31. Heiken JP, Brink JA, McClennan BL, Sagel SS, Crowe TM, Gaines MV (1995) Dynamic incremental CT: effect of volume and concentration of contrast material and patient weight on hepatic enhancement. Radiology 195:353-357

32. Behrendt FF, Pietsch H, Jost G et al (2010) Intra-individual comparison of different contrast media concentrations $(300 \mathrm{mg}, 370 \mathrm{mg}$ and $400 \mathrm{mg}$ iodine) in MDCT. Eur Radiol 20:1644-1650

33. Swindle MM, Smith AC, Laber-Laird K, Dungan L (1994) Swine in biomedical research: mamagement and models. ILAR J 36:1-5

34. Brady SL, Yee BS, Kaufman RA (2012) Characterization of adaptive statistical iterative reconstruction algorithm for dose reduction in $\mathrm{CT}$ : a pediatric oncology perspective. Med Phys 39:5520-5531 